\title{
Locally Advanced Colon Cancer with Abdominal Wall Abscess: A Challenging Case Treated by an Innovative Approach
}

\author{
Daniela Rega $^{1}$, Eleonora Cardone ${ }^{1}$, Orlando Catalano ${ }^{2}$, Luca Montesarchio ${ }^{1}$, Ugo Pace ${ }^{1}$, Dario Scala ${ }^{1}$, \\ Giovanni Conzo ${ }^{3}$, Paolo Delrio ${ }^{{ }^{*}}$ \\ ${ }^{1}$ Oncologic Colorectal Surgery, G. Pascale, National Cancer Institute, Napoli, Italy; ${ }^{2}$ Diagnostic Unit, G. Pascale, National Cancer \\ Institute, Napoli, Italy; ${ }^{3}$ General Surgery Unit, Second University of Naples, Napoli, Italy. \\ Email: *delrio.paolo@gmail.com
}

Received September $14^{\text {th }}, 2012$; revised October $13^{\text {th }}, 2012$; accepted October $22^{\text {nd }}, 2012$

\begin{abstract}
Colon cancer rarely combines with abscess of the abdominal wall. We here describe a case treated by extensive surgery, biological mesh abdominal wall repair and negative pressure therapy. A 58-year-old woman presented with a locally advanced right colon cancer with abdominal wall abscess and no evidence of distant metastasis. Extended right hemicolectomy was performed with en-bloc excision of the bladder dome, the right annex and full thickness removal of the anterior abdominal wall including the abscess. Abdominal wall repair was perfomed by a biological mesh (Permacol $^{\mathrm{TM}}$ Biologic Implant) and to facilitate healing the patient was then treated with Vacuum-Assisted Closure (V.A.C. $\left.{ }^{\circledR}\right)$ Therapy. Histology showed a mucinous moderately differentiated adenocarcinoma without nodal metastases $(\mathrm{n}=57)$. Surgical margins including the abdominal wall was tumor free. The postoperative clinical course was uneventful. V.A.C. ${ }^{\circledR}$ Therapy treatment reported excellent results in terms of active promotion of the granulation tissue, this allowing for a subsequent placement of a skin graft. Patient is alive and disease-free one year after surgery. The present case shows some peculiar characteristics such as the size of the initial lesion, the abdominal wall abscess and the use of innovative devices such as biological mesh and V.A.C. ${ }^{\circledR}$ Therapy. We demonstrate that extensive surgery for locally advanced colon cancer, in high-volume centers, provides favorable results in terms of survival and quality of life.
\end{abstract}

Keywords: Colon Cancer; Abdominal Wall Abscess; Biological Mesh; VAC Therapy

\section{Introduction}

Locally advanced colorectal cancers, a subgroup of colorectal tumors that invade adjacent organs without distant metastases, account for $5 \%-22 \%$ of all colorectal cancers [1]. Abscess formation is rare $(0.3 \%-4 \%$ of colonic cancers [2]); abscesses of the anterior abdominal wall as a complication of direct invasion and perforation of the colonic tumour have also been described [2,3]. Rarely a radical excision was performed due to the high risks of an extensive surgery and therefore prognosis is always poor.

We here report a case of a patient with locally advanced right colon cancer and abdominal wall abscess, treated with "curative" surgery. The good final outcome was favoured by the integration of surgery with innovative medical devices such as a biological mesh and Vacuum-Assisted Closure (V.A.C. ${ }^{\circledR}$ ) Therapy (KCI, San Antonio TX, USA).

\footnotetext{
*Corresponding author.
}

\section{Case Report}

A 58-year female, with recent finding of skin oedema and reddening in the right flank, was seen in a district hospital and diagnosed a locally advanced right colon cancer invading the abdominal wall. She was deemed unfit for radical surgery and referred to medical oncologists. After two cycles of chemotherapy (Folfox 4), she developed acute skin necrosis with a tender inflamed area in the right flank, suggesting an abscess. Chemotherapy was stopped and the patient referred to our hospital. A computed tomography (CT) scan showed a large solid mass in the pelvis $(12 \times 6 \mathrm{~cm})$, with internal liquefactive areas. The mass was not separable from the cecum and the distal ileal loops, with an evident fistulous tract to the bladder. Spreading into the abdominal wall and a diffuse lymph-node involvement (obturatory, external iliac, and inguinal stations) were detected. Colonoscopy confirmed an obstructing mass of the right colon. CEA level was normal. Patient underwent drainage of the 
abdominal wall abscess under local anesthesia. Surgery was then planned: an extended right hemicolectomy with en-bloc excision of the bladder dome, the right annex and full thickness resection of the anterior abdominal wall, including the abscess area $(30 \times 38 \mathrm{~cm})$, was performed (Figure 1(a)). Abdominal wall repair was carried out by inserting a biological mesh (Permacol ${ }^{\mathrm{TM}}$ Biologic Implant, Covidien, Dublin, IRL) between the right anterior rectum muscle and the lateral abdominal wall muscles (Figure 1(b)). The V.A.C. ${ }^{\circledR}$ Therapy System was immediately settled in place and started at $-125 \mathrm{mmHg}$ (with a V.A.C.GranuFoam ${ }^{\circledR}$ Large Dressing Kit) (Figure 1(c)). The V.A.C. ${ }^{\circledR}$ dressing was changed every 72 hours under general anesthesia for the initial two weeks. The patient had a remarkable recovery and was discharged at day 24th after surgery. Outpatient change of the dressing without anesthesia was performed for additional 3 weeks with a significant reduction of the wound size. The amount of aspirated fluid dropped from $500 \mathrm{mls} /$ day to $30 \mathrm{mls} /$ day in seven weeks. The size of the dressing kits was progressively reduced and complete healing was achieved within 52 days after surgery, with a full coverage of the biological mesh by granulation tissue (Figure 2(a)). Placement of skin graft removed from the thigh was then performed (Figure 2(b)). Histology showed a mucinous (dominant) node negative $(\mathrm{n}=57)$ moderately differentiated adenocarcinoma. Surgical margins includeing the abdominal wall were tumor free. After one year from surgery patient is alive and disease free.

\section{Discussion}

Few cases of locally advanced right colon cancer with abdominal wall abscess have been reported in the literature. Extreme surgical approaches are described with a high related mortality $[1,4,5]$. Radical resection is difficult due to extensive local infiltration and the need to perform multivisceral resection, often in patients with bad general conditions. Reconstruction of the abdominal wall is mandatory in case of resection extended to the muscles and fascia. Primary repairs often lead to unacceptable high tension and failure of the reconstruction is as high as $12 \%$ - 50\% [6,7]. Furthermore, large, fullthickness, abdominal wall defects secondary to wide resection of malignant tumors cannot be closed primarily. In these cases, mesh repair is preferable to obtain a tension-free abdominal wall closure. The use of prosthetic mesh reduces the recurrence rate but is also associated with serious complications in $10 \%-15 \%$ of cases [8]. In particular, when a synthetic mesh is applied to contaminated wounds, its removal is required in $50 \%-90 \%$ of the cases $[9,10]$. Generally speaking, the presence of local infection is a contraindication to any reconstructive procedure, primarily those involving flaps and prosthetic meshes.

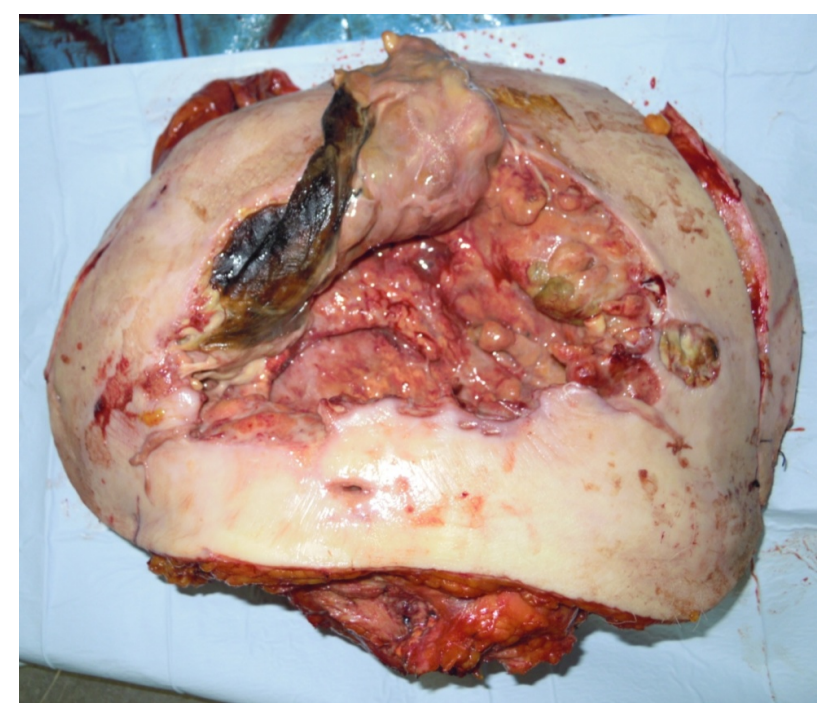

(a)

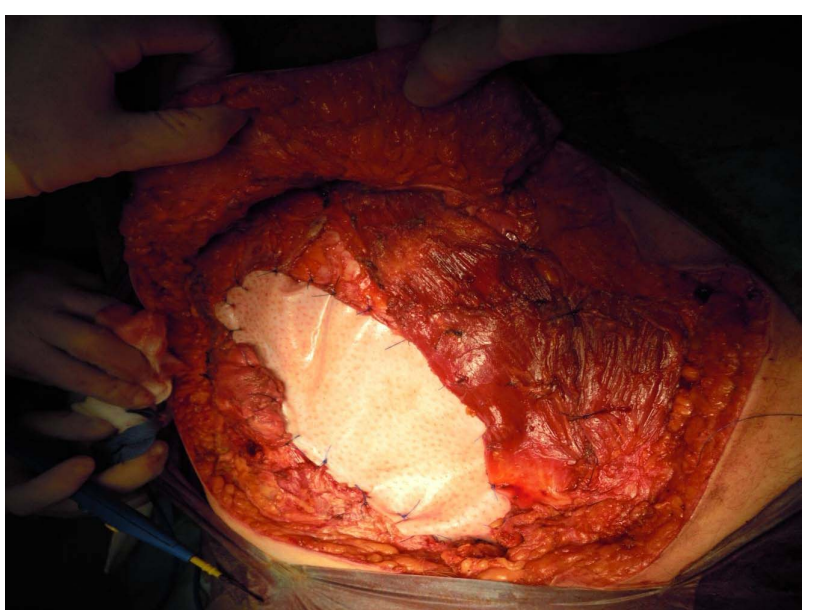

(b)

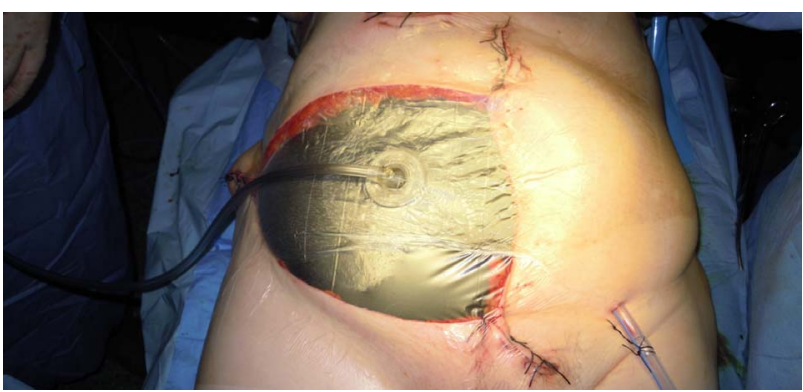

(c)

Figure 1. (a) Specimen; (b) Abdominal wall repair perfomed by biologic implant; (c) Vacuum assisted closure (V.A.C. ${ }^{\circledR}$ ) therapy system.

Thus many patients who would benefit of an aggressive surgical approach are deemed inoperable. Even in patients without metastatic disease, the prognosis remains poor due to the inability to perform a radical surgery.

In the reported case we achieved a radical resection by 


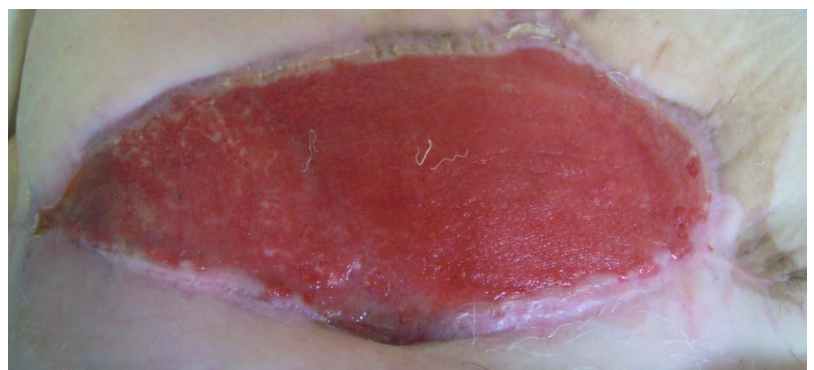

(a)

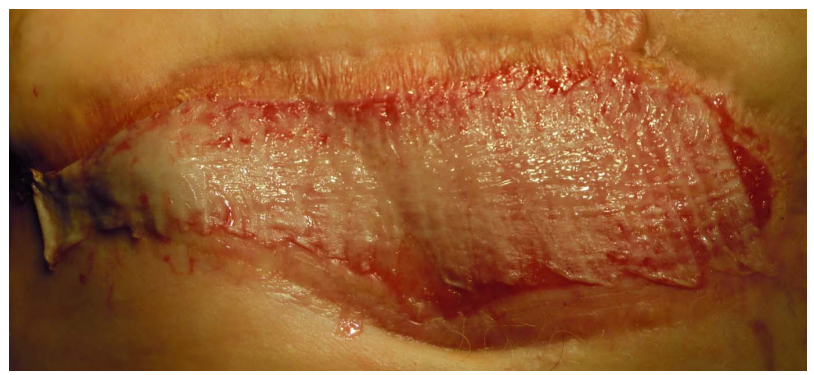

(b)

Figure 2. (a) Wound on 52th day; (b) Placement of skin graft.

an extended multivisceral resection, including a large area of the abdominal wall. The size of the abdominal wall defect and the contamination of the site represented a challenging problem. In order to minimize mesh contamination, a biological mesh (Permacol ${ }^{\mathrm{TM}}$ ) was used. Permacol $^{\mathrm{TM}}$ is supposed to better react with local tissues also in presence of bacteria: it is derived from porcine dermal collagen and the non-synthetic nature allows the mesh to be more resistant to infections. It supports fibroblast infiltration and neovascularization and as a result of its manufacturing peculiarity of cross-linking, its remodeling process is delayed in the host tissue, which provides additional strength [11-13].

Vacuum therapy has been proposed to help local healing with tissue regeneration, faster growth of granulation tissue and quicker filling of large tissue defects. Controlled negative pressure, combined with an interface in polyurethane foam, helps to make the flaps come near and allows a mechanical stretching at the cellular level resulting in increased cellular mitosis, with a faster healing [14]. Moreover the removal of excess fluids decreases the bacterial colonization of the wound bed [15].

Our patient well tolerated the dressing procedures and most of the healing process was completed with outpatient visits.

Our experience suggests that the integration of a biological mesh with V.A.C. ${ }^{\circledR}$ Therapy may guarantee a good reconstructive process, leading to a quick recovery, a shorter hospital stay and good results in patients with locally advanced colon cancer requiring extensive surgery.

\section{REFERENCES}

[1] H. Y. Hung, C. Y. Yeh, C. R. Changchien, J. S. Chen, C. W. Fan, R. Tang, P. S. Hsieh, W. S. Tasi, Y. T. You, J. F. You, J. Y. Wang and J. M. Chiang, "Surgical Resection of Locally Advanced Primary Transverse Colon CancerNot a Worse Outcome in Stage II Tumor,” International Journal of Colorectal Disease, Vol. 26, No. 7, 2011, pp. 859-865.

[2] Okita, Y. Kubo, M. Tanada, A. Kurita and S. Takashima, "Unusual Abscesses Associated with Colon Cancer: Report of Three Cases,” Acta Medica Okayama, Vol. 61, No. 2, 2007, pp. 107-113.

[3] K. John, U. Gur and D. Cade, "Carcinoma of Sigmoid Colon Presenting as Abdominal Wall Abscess," Indian Journal of Gastroenterology, Vol. 21, No. 3, 2002, pp. 117-118.

[4] W. E. Kelley Jr., P. W. Brown, W. Lawrence Jr. and J. J. Terz, "Penetrating Obstructing, and Perforating Carcinomas of the Colon and Rectum," Archives of Surgery, Vol. 11, No. 4, 1981, pp. 381-384.

[5] S. B. Eisenberg, W. G. Kraybill and M. J. Lopez, "LongTerm Results of Surgical Resection of Locally Advanced Colorectal Carcinoma,” Surgery, Vol. 108, No. 4, 1990, pp. 779-85; discussion pp. 785-786.

[6] J. W. Burger, R. W. Luijendijk, W. C. Hop, J. A. Halm, E. G. Verdaasdonk and J. Jeekel, "Long-Term Follow-Up of a Ran-Domized Controlled Trial of Suture versus Mesh Repair of Incisional Hernia,” Annals of Surgery, Vol. 240, No. 4, 2004, pp. 578-83; Discussion pp. 583-585.

[7] K. M. Millikan, “Incisional Hernia Repair,” Surgical Clinics of North America, Vol. 83, No. 5, 2003, pp. 12231234. doi:10.1016/S0039-6109(03)00129-4

[8] B. Buinewicz and B. Rosen, “Acellular Cadaveric Dermis (AlloDerm): A New Alternative for Abdominal Hernia Repair,” Annals of Plastic Surgery, Vol. 52, No. 2, 2004, pp. 188-194. doi:10.1097/01.sap.0000100895.41198.27

[9] S. R. Szczerba and G. A. Dumanian, "Definitive Surgical Treatment of Infected or Exposed Ventral Hernia Mesh," Annals of Surgery, Vol. 237, No. 3, 2003, pp. 437-441. doi:10.1097/01.SLA.0000055278.80458.D0

[10] G. Peppas, I. D. Gkegkes,M. C. Makris and M. E. Falagas, "Biological Mesh in Hernia Repair, Abdominal Wall Defects, and Reconstruction and Treatment of Pelvic Organ Prolapse: A Review of the Clinical Evidence," Annals of Surgery, Vol. 76, No. 11, 2010, pp. 1290-1299.

[11] Cavallaro, E. Lo Menzo, M. Di Vita, A. Zanghì, V. Cavallaro, P. F. Veroux and A. Cappellani, "Use of Biological Meshes for Abdominal Wall Reconstruction in Highly Contaminated Fields," World Journal of Gastroenterology, Vol. 16, No. 15, 2010, pp. 1928-1933. doi:10.3748/wjg.v16.i15.1928

[12] D. M. Parker, P. J. Armstrong, J. D. Frizzi and J. H. North Jr., "Porcine Dermal Collagen (Permacol) for Abdominal Wall Reconstruction," Current Surgery, Vol. 63, No. 4, 2006, pp. 255-258. doi:10.1016/j.cursur.2006.05.003

[13] C. B. Chuo and S. S. Thomas, “Absorbable Mesh and Topical Negative Pressure Therapy for Closure of Ab- 
dominal Dehiscence with Exposed Bowel,” Journal of Plastic, Reconstructive \& Aesthetic Surgery, Vol. 61, No. 11, 2008, pp. 1378-1381. doi:10.1016/j.bjps.2007.04.012

[14] T. Bjarnason, A. Montgomery, J. Hlebowicz, S. Lindstedt and U. Petersson, "Pressure at the Bowel Surface during Topical Negative Pressure Therapy of the Open Abdomen: An Experimental Study in a Porcine Model," World
Journal of Surgery, Vol. 35, No. 4, 2011, pp. 917-923. doi:10.1007/s00268-010-0937-y

[15] M. D’Hondt, A. D’Haeninck, L. Dedrye, F. Penninckx and R. Aerts, "Can Vacuum-Assisted Closure and Instillation Therapy (V.A.C.-Instill Therapy) Play a Role in the Treatment of the Infected Open Abdomen?” Techniques in Coloproctology, Vol. 15, No. 1, 2011, pp. 75-77. doi:10.1007/s10151-010-0662-4 